\title{
RECENT PROBLEMS AND STRATEGIES IN THERMOCHEMISTRY
}

\author{
Cecil E. VANDERZEe \\ Department of Chemistry, University of Nebraska, Lincoln, NB 68588 USA
}

\begin{abstract}
Current trends in thermochemistry involve increasingly complex reaction systems and product mixtures in which equilibria exist or in which competing reactions are part of the source of energy in the process. Illustrations are provided for reduction to the standard state process of results obtained when hydrolyzing solutes or weak electrolytes are present, by secure pathways making maximum use of attainable guidance in reaching the reference state. The hydrolyzing systems illustrated are mercuric perchlorate, sodium bicarbonate, and sodium carbonate solutions. The utilization of enthalpy-of-mixing data is also illustrated, and problems relating to the standard state for solids are discussed.
\end{abstract}

In this presentation I shall try to confine my remarks to the subject of thermochemistry, or the energy (enthalpy) changes associated with chemical changes. Such a distinction must be arbitrary, and is not a restraint upon the experimentalist, who must also be aware of developments in the other subject areas of this conference. There is much to be learned from tactics and instrumentation developed to study new areas, or old areas with more accuracy or more efficiency. The continuing development of new calorimeters and improved instrumentation is revealed each year in that part of the bibliography section of the Bulletin of Thermodynamics and Thermochemistry, and in the new ideas revealed at conferences on thermodynamics at their regular meetings.

Surely one of the fascinating results of such ingenuity is the development of small calorimeters. We are meeting close to where Albert Tian and Edouard Calvet pioneered in microcalorimetry, and where Dr. Lafitte and his colleagues continue those efforts. The experimentalist now has a choice from several commercial models for study of slow phenomena or for study of processes with small amounts of sample. But miniaturization has spread to other types of calorimetry. I can give only a few examples, and I apologize for omissions. Special mention must be made of a $4.5 \mathrm{~cm}^{3}$ combustion bomb calorimeter developed by Månsson and Sunner, ${ }^{1}$ together with techniques yielding results essentially equal to those with conventional scale instruments. Christensen, Izatt and colleagues ${ }^{2,3}$ have recently reported a solution calorimeter with a $3.5 \mathrm{~cm}^{3}$ vessel for both batch and titration calorimetry. Picker, Desnoyers et $a l^{4}{ }^{4}$ have developed flow calorimeter techniques which enable extensive high accuracy heat capacity measurements and enthalpy-of-mixing measurements to be made on quite small amounts of material. Scanning calorimeters have been reported in such numbers that I shall refrain from selecting an example, but several achieve accuracy approaching that of conventional static instruments, and I presume that Professor Privalov will touch on this area in his presentation to this conference.

Successful development of small calorimeters permits study on scarce or expensive materials that could not otherwise be studied with normal-sized instruments. Rapidly increasing use of calorimetry for study of biological materials and processes has been both a result and a cause of such developments. At the same time, such studies often involve systems of high complexity, and new problems arise which concern identifying the real sources of the thermal effects in the systems.
Reaction calorimetry at high temperatures or high pressures, or both, remains the province of a few bold investigators. Kleppa ${ }^{5}$ and his colleagues recently described high temperature combustion calorimetry on titanium oxides. Olofsson and Sunner ${ }^{6,7}$ have developed a constant volume calorimeter for reactions in solutions up to $400 \mathrm{~K}$ and $800 \mathrm{kPa}$, and at this conference a high temperature reaction calorimeter developed by Cobble and his group will be described. ${ }^{8}$ Closed calorimeters for heat capacity studies on liquids and solutions at elevated temperatures have been reported frequently in the past 10-15 yr, and development of reaction calorimeters for use at such conditions is quite overdue.

With the increasing interest in the properties of solutions, especially electrolytes, at extreme temperatures and/or pressures, more such investigations may be expected in the future, and more work will be done with closed or sealed calorimeters to avoid evaporation effects. Theories and models of electrolyte solutions are inadequate for extending properties much beyond the range of measurement, and current attempts at this have great need of guidance from more secure and extensive data. Heat capacity measurements on solutions are first priority, and extension of flow or drop calorimetry to higher temperatures is to be expected. For biological systems characterization at $35-38^{\circ} \mathrm{C}$ is highly desirable or even mandatory in many cases, and there is need for the interconnecting data to make the current bodies of information, mostly at $25^{\circ} \mathrm{C}$, more useful for the study of such systems.

The experimentalist has two major problem areas. The first is to measure the thermal response with desired sensitivity and accuracy, to extract from his results the small inputs of heat and work from the surroundings of the calorimeters, and to identify the temperature for the isothermal process under study. New and special instrumentation, coupled with accumulated experience and careful, critical analysis, normally solves this problem and at the same time increases the range of opportunities. The second major problem is to determine the amount of substance reacting and to identify the actual processes which occur during the calorimetric experiment. It is painful to realize that attainable purity may set the real uncertainty limits for the experiment, or that the analytical procedures may set those limits, but such is often the case. (Perhaps "usually the case" would be more realistic.) Even when purity is well established by assay, crystals frequently may still deviate from their "standard state" due to strain energies, lattice defects, 
high surface energy, or even small deviations in stoichiometry, as for metallic oxides and similar compounds which are "polymeric" in nature. For many of us engaged in such work, eternal vigilance and skepticism is an essential part of the experimental procedure. Combustion calorimetry makes special demands on the chemical skills of the thermochemist, but those in other fields of calorimetry are really equally challenged.

The importance of the second problem depends on the purpose of the thermochemist. When the goal is to characterize a process or study the properties of the total system, as in biological thermochemistry or in the study of mixture properties, then often the analytical techniques may be adequate, or may simply be accepted. However, when the goal is to measure the thermodynamic property of a particular compound or a particular designated reaction, then special demands are made on the analyses and measures of composition, in order to provide the information needed to reduce the results to the standard state process.

It is to this situation that I address my remaining comments, for we are not simply thermochemists, or thermophysicists, or biological calorimetrists, or some other restrictive classification. Instead, we are thermodynamicists, and the information we produce by measurement can and should be woven into the total web of thermodynamic description of chemical and physical systems. Our information is most useful if it can be transformed or reduced to description of standard state processes, to facilitate compilation, storage, retrieval, and reuse of the information. Certainly our measurements are the more useful when they can contribute to such transformations. Moreover, the users of thermodynamic data often are working at conditions quite removed from standard state conditions, and I sympathize with the complaint of an engineer or process designer that much of our reported accuracy does him little good because data for transformation to processes at high temperatures, or high concentrations in complex mixtures, must still be guessed at, or may be almost impossible to find. Remembering this, we have more appreciation for the work of those who measure heat capacities, or study the properties of mixtures such as enthalpies of mixing or dilution, or other properties relating to Gibbs energies of the components, for such studies are essential to description of equilibrium states and equilibrium constants. We must even remember that part of electrochemistry is thermodynamic in character. In whatever special area we work, we must maintain the broad perspective of thermodynamicists.

As an illustration, consider the reduction of mercuric oxide by hydrogen to form mercury and water:

$$
\mathrm{H}_{2}(\mathrm{~g})+\mathrm{HgO}(\mathrm{s})=\mathrm{Hg}(1)+\mathrm{H}_{2} \mathrm{O}(1) \text {. }
$$

This reaction might seem to be well suited for study by hot-zone reaction calorimetry, such as pacticed by Pilcher and Skinner,' but apparently it has not been so studied, and there is an obvious complication: possible loss of mercury vapor from the reaction zone and the calorimeter. This reaction has been the subject of several careful e.m.f. studies, and interpretation of the results by Cobble's "third-law" method ${ }^{10}$ gives consistent values for the enthalpy change, especially since the individual entropies of the substances are available at good accuracy. The standard state for mercuric oxide is the red orthorhombic crystal, so care was needed to identify the studies made with the desired crystalline form. Dissolution of the mercuric oxide in perchloric acid then should provide a direct path to the enthalpy of formation of the $\mathrm{Hg}(\mathrm{II})$ ion:

$$
\mathrm{HgO}(\mathrm{s})+2 \mathrm{HClO}_{4}(\mathrm{aq})=\mathrm{H}_{2} \mathrm{O}(\mathrm{l})+\mathrm{Hg}^{2+}(\mathrm{aq})+2 \mathrm{ClO}_{4}^{-}(\mathrm{aq}) \text {. }
$$

But immediately two ugly problems raise their heads: (1) the calorimetric process is too slow for accurate results unless a substantial excess of acid is used; (2) the $\mathrm{Hg}$ (II) ion hydrolyses extensively, even when some excess acid is present. Consequently, it is not possible to measure enthalpies of dilution on pure $\mathrm{Hg}$ (II) perchlorate solutions to concentrations low enough to reach the standard reference state by ordinary extrapolation methods, and in any case, we have a product mixture to reduce to the standard state. We considered a number of ways to slay these twin dragons, and finally settled on the following strategy. ${ }^{11}$

Enthalpies of dilution for electrolytes are converted to relative apparent molar enthalpies, $L_{\phi}$, by extrapolation of apparent enthalpies to infinite dilution with guidance from equations based on the Debye-Hückel theory. ${ }^{12}$ The extrapolation reduces to zero the deviation from ideal solution behavior, and the conventional reference state, at infinite dilution, permits equating the enthalpy of formation of the electrolyte to the sum of the enthalpies of formation of the constituent ions. Such extrapolation goes astray when hydrolysis occurs, so hydrolysis must be wholly suppressed or else corrected for at each composition studied. The Debye-Hückel equations ${ }^{12}$ predict that for non-hydrolyzed, non-associating electrolyte mixtures, the total relative apparent enthalpy is the sum of the relative apparent enthalpies of the pure components at the ionic strength of the mixture. It is an "additivity rule" which assumes no enthalpy change if electrolytes are mixed at constant ionic strength. Tests of the addivity rule by Young, Wu and Krawetz ${ }^{13}$ and by Wood et al. ${ }^{14}$ indicate that small enthalpies of mixing do occur, but the overall effect can be expected to vanish at zero ionic strength.

Our measurement ${ }^{11}$ of the enthalpy of solution of $\mathrm{HgO}(\mathrm{s})$ in $\mathrm{HClO}_{4}$ yielded a product mixture with composition $\mathrm{Hg}\left(\mathrm{ClO}_{4}\right)_{2} \cdot 9.80 \mathrm{HClO}_{4} \cdot \mathrm{bH}_{2} \mathrm{O}$. We then measured enthalpies of dilution of this mixture into water and referred the resulting apparent molar enthalpies (19 measurements) to a single curve. The effects of hydrolysis were clearly evident at ionic strengths below $0.04 \mathrm{~mol} \mathrm{~kg}^{-1}$ where the $\mathrm{HClO}_{4}$ molality was below $0.03 \mathrm{~mol} \mathrm{~kg}^{-1}$. The data were corrected for hydrolysis, with corrections based on enthalpies of hydrolysis measured by Arnek and Kakolowicz, ${ }^{15}$ with the extent of hydrolysis based on equilibrium constants from the literature $\mathrm{e}^{16}$ and estimated activity coefficients. ${ }^{11}$ These auxiliary data were less accurate than desired. However, the corrected curve for $L_{\phi}$ for the mixture could be guided to the reference state by analog curves constructed from $L_{\phi}\left[\mathrm{Mg}\left(\mathrm{ClO}_{4}\right)_{2}\right]+$ $9.80 \mathrm{~L}_{\phi}\left(\mathrm{HClO}_{4}\right)$. Other analogs were tested, but this was clearly the closest representation then available, and was expected from similarities revealed by enthalpies of solution measured by Shchukarev et al. ${ }^{17-19}$ at high concentrations. The implication is strong that $L_{\phi}$ for $\mathrm{Hg}\left(\mathrm{ClO}_{4}\right)_{2}$ solutions closely imitates that for $\mathrm{Mg}\left(\mathrm{ClO}_{4}\right)_{2}$ solutions. Subsequent measurements made in our laboratory ${ }^{20-23}$ on several $2-1$ perchlorates reveal close similarities in the $L_{\phi}$ curves for the strongly hydrated 
cations such as $\mathrm{Mg}^{2+}, \mathrm{Mn}^{2+}, \mathrm{Co}^{2+}, \mathrm{Ni}^{2+}, \mathrm{Zn}^{2+}$ and $\mathrm{Cd}^{2+}$. The use of analog curves for guidance in extrapolation is a better strategy for the $\mathrm{Hg}\left(\mathrm{ClO}_{4}\right)_{2} \cdot 9.80 \mathrm{HClO}_{4}$ mixture than direct application of Debye-Hückel functions because the analog curves provide guidance over a much greater range of ionic strength and are automatically adjusted to the proper limiting slope and curvature effects from ion size factors and other factors as well. (The components of the analog curve had previously been fitted by the Debye-Hückel functions, of course.) As reported in Ref. 11, the extrapolation for the mixture was judged to be reliable within $\pm 40 \mathrm{cal} \mathrm{mol}^{-1}$ even from regions of concentration where hydrolysis was strongly suppressed, and demonstrates that one can attain the conventional reference state by reliable routes even for such a difficult system. At the same time, the reported $L_{\phi}$ data for the mixture should be useful for other studies on $\mathrm{Hg}\left(\mathrm{ClO}_{4}\right)_{2}$ solutions. All that is needed is a mixing experiment to provide a mixture with a composition $\mathrm{Hg}\left(\mathrm{ClO}_{4}\right)_{2} \cdot 9.80 \mathrm{HClO}_{4}$ in the range of the data. Then, the upper curve in Fig. 1, Ref. 11, represents values for correcting the mixtures to the conventional reference states, and includes the corrections for both hydrolysis and dilution. (Numerical values would be available from $\left[L_{I}(\mathrm{obs})-60\right] / \mathrm{cal} \mathrm{mol}^{-1}$, column 3, Table 5, Ref. 11).

Certainly a more useful tactic involves direct measurements of the excess enthalpy of mixing at constant ionic strength, when such measurements are possible. The results of such measurements can be represented by

$$
\Delta_{m} \mathrm{H}^{\mathrm{E}}=a_{1} a_{2} m_{2}\left[A+\left(1-2 y_{2}\right) B\right]
$$

where $\Delta_{m} \mathrm{H}^{\mathrm{E}}$ is scaled to unit amount of primary substance (subscript 1). The valence factors $a$ are 1 for 1-1 electrolytes, 3 for 2-1 electrolytes, etc. $A$ and $B$ are constants for the particular system and ionic strength, and $y_{2}$ is the ionic strength fraction for the second component. In terms of the mole ratio $r=n_{2} / n_{1}$ and the ionic strength I,

$$
a_{1} a_{2} m_{2}=a_{1} a_{2} r I /\left(a_{1}+a_{2} r\right) .
$$

These equations reveal that, when $\Delta_{m} \mathrm{H}^{\mathrm{E}}$ is referred to the major component in the mixture and $r$ is small, the term $\Delta_{m} \mathrm{H}^{\mathrm{E}}$ is usually small and that little error results from representing the relative apparent molar enthalpy for a mixture by the appropriate weighted sum of terms for the components at the same ionic strength. Gier has verified that for $r=0.069$ in $\mathrm{Ni}\left(\mathrm{ClO}_{4}\right)_{2}+\mathrm{HClO}_{4}$ mixtures there is little perturbation from the excess acid, and our studies on metal perchlorates ${ }^{20-22}$ were made with small traces of $\mathrm{HClO}_{4}$ present to suppress hydrolysis of the metal ions.

However, when the primary substance in the reaction is the minor component, then $\Delta_{m} \mathrm{H}^{\mathrm{E}}$ is not negligible. We have measured $\Delta_{m} \mathrm{H}^{\mathrm{E}}$ for $\mathrm{Zn}\left(\mathrm{ClO}_{4}\right)_{2} \cdot r \mathrm{HClO}_{4}$ mixtures ${ }^{23}$ in connection with studies of the enthalpies of solution of $\mathrm{ZnO}(\mathrm{s})$ in excess $\mathrm{HClO}_{4}{ }^{24}$ In the solution, the molality of $\mathrm{Zn}\left(\mathrm{ClO}_{4}\right)$ was between 0.018 and $0.023 \mathrm{~mol} \mathrm{~kg}^{-1}$, and $r$ varied from 1.1 to 58 . The results revealed that $\Delta_{m} \mathrm{H}^{\mathrm{E}}$ for such mixtures was a slowly varying quadratic function of the molality of $\mathrm{HClO}_{4}$,

$$
\Delta_{m} \mathrm{H}^{\mathrm{E}}=285 m_{2}-133 m_{2}^{2}
$$

where $m_{2}$ is molality $\left(\mathrm{mol} \mathrm{kg}^{-1}\right)$ and $\Delta_{m} \mathrm{H}^{\mathrm{E}}$ is in cal mol${ }^{-1}$. These results reveal the magnitudes to be expected from this correction term, but one must avoid predictions for other systems at this point. Values of $\mathrm{H}^{\mathrm{E}}$ reported by Wood and his colleagues ${ }^{14}$ are referred to unit amount (kg) of solvent, and are converted to $\Delta_{m} \mathrm{H}^{\mathrm{E}}$ by division by $m_{1}$, the molality of the primary substance in the reaction of interest. (The primary substance is that to which $\Delta \mathrm{H}_{r}$ is referred.) Not only is there a clear need for more mixing studies of this type, but there is also a need for greater recognition of the potential value of such data in thermochemical studies yielding multicomponent mixtures. We can hope that some of the mixing-flow calorimeters which have been reported will increase the output of needed data, for such instruments are clearly the most efficient for the purpose.

The efficiency of enthalpy-of-dilution measurements can be increased several-fold by titration calorimetry instead of or in conjunction with conventional batch techniques with ampoules. We rig our calorimeter for titration procedures by appropriate fittings in the lid of the calorimeter, and deliver the solution in measured pulses. ${ }^{12}$ Each pulse is treated by conventional time-temperature measurements as for batch operations. The advantages are retention of simplicity and maximum accuracy, ease of calculation and referral to the isothermal calorimetric process, and several-fold increase in efficiency. Batch operations with ampoules are used to characterize solutions at higher molalities, and the titration results are used to delineate the low concentration region. Multiple ampoule techniques are also employed. To be sure, flow calorimetric techniques can also be used to measure enthalpies of dilution, and such applications will undoubtedly increase in the future. Messikomer and Wood ${ }^{25}$ have recently reported a flow calorimeter for measuring enthalpies of mixing and dilution up to $373 \mathrm{~K}$.

The question may well be raised at this point: "Why must solution thermodynamics be dependent on the Debye-Hückel theory of electrolytes?" It is a fair question. In answer, first of all we do need an extrapolation guide from the range of practical concentrations down to the conventional reference state of infinite dilution, and the theory has yielded a convenient guide, both for Gibbs energy deviations (activity coefficients) and excess enthalpy deviations. The guiding equations are based on the same model, so are internally consistent if one is careful to use consistent parameters. Indeed, the conventional reference state for electrolytes might be described as the "ideal dilute Debye-Hückel state", and it is this state to which practically all of the measured properties of electrolytes have been referred. We have no practical substitute at present. If at some future time the theory is superseded by a new model with significantly different functions, much recalculation of existing data must then inevitably result. The burden of such readjustments would be much reduced if we make consistent use of the present guidance functions now. The DebyeHückel functions which we have been using are based on the Owen and Brinkley treatment, ${ }^{26}$ and we have retained the term involving variation of the ion-size parameter with temperature. $^{12}$ Our experience with this equation for many electrolytes is that the temperature coefficient of the ion-size parameter is small enough to be neglected in most cases, with substantial simplification of the equation. Computer techniques are normally used to fit the experimental data, so it is desirable to retain the ion size parameter based on activity coefficient data as a property for the individual electrolyte, rather than to use an "average value" of some sort. My plea is simply this, that we use the best guidance functions available, or analogs 
based thereon, to maintain as much internal consistency as possible in the treatment of electrolyte properties.

The problem of hydrolysis or solvolysis of a solute is a serious one in solution thermochemistry, because the perturbing effects increase as one seeks to approach the reference state. Consider the steps involved in seeking the standard enthalpy of solution of such a salt, $\mathrm{NaX}(\mathrm{s})$.

$$
\begin{gathered}
\mathrm{NaX}(\mathrm{s})+a \mathrm{H}_{2} \mathrm{O}(1)=(1-\alpha)\left(\mathrm{Na}^{+}+\mathrm{X}^{-}\right) \cdot \alpha\left(\mathrm{Na}^{+}+\mathrm{OH}^{-}\right) \\
\cdot \alpha \mathrm{HX} \cdot(a-\alpha) \mathrm{H}_{2} \mathrm{O} \\
(1-\alpha)\left(\mathrm{Na}^{+}+\mathrm{X}^{-}\right) \cdot \alpha\left(\mathrm{Na}^{+}+\mathrm{OH}^{-}\right) \cdot \alpha \mathrm{HX} \cdot(a-\alpha) \mathrm{H}_{2} \mathrm{O} \\
+\infty \mathrm{H}_{2} \mathrm{O}(\mathrm{l}) \\
=(1-\alpha)\left(\mathrm{Na}^{+}+\mathrm{X}^{-}\right) \cdot \alpha\left(\mathrm{Na}^{+}+\mathrm{OH}^{-}\right) \cdot \alpha \mathrm{HX} \cdot \infty \mathrm{H}_{2} \mathrm{O}
\end{gathered}
$$

$$
\begin{aligned}
\alpha\left(\mathrm{Na}^{+}+\mathrm{OH}^{-}\right) \cdot \alpha \mathrm{HX} & \cdot \infty \mathrm{H}_{2} \mathrm{O} \\
= & \alpha\left(\mathrm{Na}^{+}+\mathrm{X}^{-}\right) \cdot \alpha \mathrm{H}_{2} \mathrm{O} \cdot \infty \mathrm{H}_{2} \mathrm{O}
\end{aligned}
$$

The first step is the isothermal calorimetric process, for which

$$
\Delta \mathrm{H}_{\text {lcp }}=\Delta \mathrm{H}_{\text {soln }}^{\mathrm{e}}
$$

represents enthalpy of solution to form the equilibrium mixture. The second step is a transformation, at constant degree of hydrolysis $\alpha$, to the reference state of infinite dilution, for which the total enthalpy change is

$$
\Delta \mathrm{H}=-(1-\alpha) L_{\phi}\left(\mathrm{Na}^{+}+\mathrm{X}^{-}\right)-\alpha L_{\phi}(\mathrm{NaOH})-\alpha L_{\phi}(\mathrm{HX}) .
$$

The third step is restoration to the unhydrolyzed state at $\infty \mathrm{H}_{2} \mathrm{O}$, which is the conventional reference state for the electrolyte.

$$
\Delta \mathrm{H}=\alpha\left(\Delta \mathrm{H}_{\mathrm{N}}^{\circ}+\Delta \mathrm{H}_{\mathrm{ion}}^{\circ}\right)=-\alpha \Delta \mathrm{H}_{\mathrm{hydr}}^{\circ}
$$

where the enthalpy change for hydrolysis is related to that for ionization of $\mathrm{HX}, \Delta \mathrm{H}_{\mathrm{ion}}^{\circ}$, and to $\Delta \mathrm{H}_{\mathrm{N}}^{\circ}$ for recombination of the ions $\mathrm{H}^{+}$and $\mathrm{OH}^{-}$to form $\mathrm{H}_{2} \mathrm{O}$. The combined steps give the standard enthalpy of solution;

$$
\begin{aligned}
\Delta \mathrm{H}_{\text {soln }}^{\circ}= & \Delta \mathrm{H}_{\mathrm{lcp}}+\alpha\left(\Delta \mathrm{H}_{\mathrm{N}}^{\circ}+\Delta \mathrm{H}_{\mathrm{ion}}^{\circ}\right)-(1-\alpha) L_{\phi}\left(\mathrm{Na}^{+}+\mathrm{X}^{-}\right) \\
& -\alpha L_{\phi}(\mathrm{NaOH})-\alpha L_{\phi}(\mathrm{HX})
\end{aligned}
$$

or

$$
\Delta \mathrm{H}_{\text {soln }}^{\circ}=\Delta \mathrm{H}_{\text {soln }}^{\mathrm{e}}-L_{\phi}{ }^{\mathrm{e}}(\mathrm{NaX})
$$

where

$$
\begin{aligned}
L_{\phi}^{e}(\mathrm{NaX})= & \alpha\left(\Delta \mathrm{H}_{\mathrm{N}}^{\circ}+\Delta \mathrm{H}_{\mathrm{ion}}^{\circ}\right)-(1-\alpha) L_{\phi}\left(\mathrm{Na}^{+}+\mathrm{X}^{-}\right) \\
& -\alpha L_{\phi}(\mathrm{NaOH})-\alpha L_{\phi}(\mathrm{HX}) .
\end{aligned}
$$

The quantity $-L_{\phi}{ }^{e}(\mathrm{NaX})$ represents the enthalpy of transformation of the equilibrium mixture to the conventional reference state. $L_{\phi}\left(\mathrm{Na}^{+}+\mathrm{X}^{-}\right)$represents the relative apparent molar enthalpy of the ion combination $\left(\mathrm{Na}^{+}+\mathrm{X}^{-}\right)$and should behave like $L_{\phi}$ for normal strong electrolytes. $L_{\phi}(\mathrm{HX})$ refers to the neutral species $\mathrm{HX}$, and is usually a slowly varying function of ionic strength. A series of measurements of $\Delta \mathrm{H}_{\text {soln }}^{\mathrm{e}}$ at various molalities would provide a basis for extricating both $\Delta \mathrm{H}_{\text {soln }}^{\circ}$ and $L_{\phi}{ }^{\mathrm{e}}$, provided the dissociation constant of the acid $\mathrm{HX}$ and related activity coefficients are available to calculate reliable values of $\alpha$. The value of $\Delta \mathrm{H}_{\text {ion }}^{\circ}$ would be needed from other measurements, but usually $\Delta \mathrm{H}_{\mathrm{N}}^{\circ}$ is much larger than $\mathrm{H}_{\mathrm{ion}}^{\circ}$ and dominates the correction. The combined $L_{\phi}$ terms might be represented by a suitable DebyeHückel function, or an analog function might be generated as a representation. Appropriate rearrangement of terms would leave an extrapolation residue which should go to zero at $\infty \mathrm{H}_{2} \mathrm{O}$. The strategy is analogous to that practised in obtaining standard e.m.f. values for cells, or in obtaining standard equilibrium constants, and is not fundamentally different from the procedures for obtaining $\Delta \mathrm{H}_{\text {soln }}^{\circ}$ and $L_{\phi}$ for strong electrolytes (where $\alpha=0$ ). For salts which undergo limited hydrolysis, the correction term $\alpha\left(\Delta \mathrm{H}_{\mathrm{N}}^{\circ}+\Delta \mathrm{H}_{\mathrm{ion}}^{\circ}\right)$ becomes large only at low concentrations, frequently below the practical range of calorimetric studies. (The above equations apply equally well to dilution studies where a stock solution is diluted instead of dissolving the solid.)

Examination of the behavior pattern for $\mathrm{NH}_{4} \mathrm{Cl}$ reveals that $L_{\phi}{ }^{e}$ is larger than $L_{\phi}$ by about $1 \mathrm{cal} \mathrm{mol}^{-1}$ at $m=0.1 \mathrm{~mol} \mathrm{~kg}{ }^{-1}$ and $7 \mathrm{cal} \mathrm{mol}^{-1}$ at $m=0.002 \mathrm{~mol} \mathrm{~kg}^{-1}$. Below $m=0.001 \mathrm{~mol} \mathrm{~kg}^{-1}, L_{\phi}^{\mathrm{e}}$ increases rapidly to its maximum of $70 \mathrm{cal} \mathrm{mol}^{-1}$ at $m \rightarrow 0$. If the experimental data were not corrected for these hydrolysis contributions, the extrapolation to $m \rightarrow 0$ would yield an error of $10-12 \mathrm{cal} \mathrm{mol}^{-1}$ in $\Delta \mathrm{H}_{\text {soln }}^{\circ}$ and also in values of $L_{\phi}$ above $m=0.1 \mathrm{~mol} \mathrm{~kg}^{-1}$. For substances which hydrolyze even two or three times more strongly than $\mathrm{NH}_{4} \mathrm{Cl}$, the perturbation would quickly become troublesome.

In some recent work in our laboratory we have put the calculation to a severe test in measuring the enthalpies of dilution of $\mathrm{NaHCO}_{3}$ and $\mathrm{Na}_{2} \mathrm{CO}_{3}$ solutions. ${ }^{22}$ For this system, the dissociation constants are reliable and activity coefficient functions could be extricated from the studies of those constants. In separate experiments we redetermined the enthalpies of ionization. The $\mathrm{NaHCO}_{3}$ solutions are internally buffered, and the extents of hydrolysis and dissociation of $\mathrm{HCO}_{3}{ }^{-}$were small, so the total corrections ranged from 20-23 $\mathrm{cal} \mathrm{mol}^{-1}$ over the range of molalities studied, even though many correction terms are involved. The result was a quite unambiguous extrapolation and a well defined curve for $L_{\phi}$ vs $m^{1 / 2} \cdot \mathrm{Na}_{2} \mathrm{CO}_{3}$ solutions, on the other hand, undergo extensive hydrolysis, and the correction term $\alpha \Delta \mathrm{H}_{\mathrm{hydr}}^{\circ}$ becomes very large at low concentrations. Some error may well result from the inevitable uncertainties in the activity coefficients needed in the calculation of $\alpha$, and there is no escape from this problem. The results of several series of measurements, including two runs wherein hydrolysis was partially suppressed by dilution into dilute $\mathrm{NaOH}$ solutions, yielded a curve for $L_{\phi}$ with a mean deviation of $\pm 3 \mathrm{cal} \mathrm{mol}^{-1}$ at $I=0.25 \mathrm{~mol} \mathrm{~kg}^{-1}$, and $\pm 10 \mathrm{cal} \mathrm{mol}^{-1}$ at $I=0.025 \mathrm{~mol} \mathrm{~kg}^{-1}$, and about $\pm 20 \mathrm{cal} \mathrm{mol}^{-1}$ at $I=$ $0.015 \mathrm{~mol} \mathrm{~kg}^{-1}$.

Extrapolation to zero ionic strength was guided by Debye-Hückel functions and analog curves from $\mathrm{Ba}\left(\mathrm{ClO}_{4}\right)_{2}$ and $\mathrm{Na}_{2} \mathrm{SO}_{4}$. Considering the magnitude of the correction terms, the behavior of the results does indicate that even severe cases of hydrolysis can be handled. It is worth noting here that traces of dissolved $\mathrm{CO}_{2}$ in the water used as diluent, at a level of $1 \times 10^{-5} \mathrm{~mol} \mathrm{~kg}^{-1}$, would produce errors of $\pm 15 \mathrm{cal} \mathrm{mol}^{-1}$ in $\alpha \Delta \mathrm{H}_{\mathrm{hydr}}^{\circ}$ at $I=$ $0.015 \mathrm{~mol} \mathrm{~kg}^{-1}$, primarily from influence on the extent of hydrolysis, so it was necessary to monitor the batches of solvent used by analysis for $\mathrm{CO}_{2}$ under the same handling procedures, and to adjust the calculations accordingly.

Once values of $L_{\phi}$ for the ion combination $\left(2 \mathrm{Na}^{+}+\right.$ 
$\mathrm{CO}_{3}{ }^{2-}$ ) are established, we then have values for $L_{\phi}{ }^{\mathrm{e}}$ also, both referred to the conventional reference state. These quantities differ greatly in their behavior; $L_{\phi}{ }^{\mathrm{e}}$ must rise to a maximum of $11,940 \mathrm{cal} \mathrm{mol}^{-1}$ at $m \rightarrow 0$. Both sets of values should be useful. The $L_{\phi}^{\mathrm{e}}$ values represent the transformation from the reference state to the equilibrium state for the pure solutions, and we have used them in calculating the standard enthalphies of solution for $\mathrm{Na}_{2} \mathrm{CO}_{3}$ (s) from several measurements reported in the literature. Differences in $L_{\phi}^{\mathrm{e}}$ values represent actual enthalpies of dilution. The values of $L_{\phi}$ for the ions are applicable to mixtures containing $\mathrm{Na}_{2} \mathrm{CO}_{3}$ as a component, and we used these values in refining our calculations on the enthalpy of hydrolysis of $\mathrm{CO}_{3}{ }^{2-}$ and on reducing to standard states the results of our measurements on the enthalpy of solution of gaseous carbon dioxide in an excess of aqueous sodium hydroxide. (I will discuss those measurements at another session of this conference.)

We are continuing this line of work on other weak electrolyte systems. Work on the phosphates is underway, and is every bit as involved as for the carbonates, but we now have some experience to guide us in planning the most appropriate measurements. Obviously there is no end to opportunities for exploration in this area.

In summary, there is need for values of both $L_{\phi}$ and $L_{\phi}{ }^{e}$ for weak electrolytes, to serve two different sets of purposes. The conventional enthalpies $L_{\phi}$ will be useful in application of the additivity concept in studies of transformations in mixtures, and the equilibrium enthalpies for joining the equilibrium state to the conventional reference state and pure substance standard state.

Certainly if we are to try to relate to standard states some of the results obtained in the calorimetry of biological systems, we shall need much data of this kind. There are analogous problems with associating solutes, culminating in strong complex ion formation. In some of these cases, the routes to standard states may prove to be impassable.

I have dealt with the solution state of a dissolving process, but there are analogous problems relating to the state of the solid and the reproducibility of the solid crystalline state. How can we be certain that our solid samples are in the true thermodynamic standard state? Crystal strain energies are probably quite small for organic solids, but inorganic crystals, on the other hand, may retain appreciable distortion energy from previous treatment, lattice imperfections, impurity effects, and perhaps large surface energy. How often have our energies contained a contribution from heat-of-wetting? And how large are such effects? How often have the effects of non-stoichiometry been a part of what we have measured? These complications are as much a part of the thermochemist's problems as are the effects of hydrolysis, or other parasitic reactions, in solution-reaction calorimetry. They might be regarded as the solid state analog, except that they are often non-equilibrium conditions. It is here that the thermochemist has strong mutual interests with those who study the thermal, physical, and chemical properties of the solid state. We can hope that the continuing development of specialized calorimeters for studying such properties, and for studying slow transformations in solids, will provide new guidance to the preparation of samples representative of the true standard state. For real challenges-let us consider the metal oxides!

Perhaps as thermochemists we should change our sampling patterns. Usually we make our measurements on one sample of material. Perhaps we should challenge fate more often, and use samples from several sources, each with different histories, carefully noted and documented, to expose non-representative behavior if it is present, and to provide some quantitative measure of the energy differences.

There are many areas in which thermochemists have mutual interests, but certainly one of the areas which requires mutual attention is that of combustion in a bomb of organometallic compounds, or compounds containing silicon, or phosphorus. The final states are mixtures of complex composition in many cases, and there is much to be done in providing secure paths to standard state processes. Solutions to these problems will require broadening of our interests and awareness of the interdependence between areas of thermochemistry. It is for that purpose that we are here.

\section{REFERENCES}

${ }^{1}$ M. Månsson, J. Chem. Thermodynamics, 5, 721 (1973).

${ }^{2}$ L. D. Hansen, R. M. Izatt, D. J. Eatough, T. E. Jensen and J. J. Christensen, Anal. Calorimetry, 3, 7 (1974).

${ }^{3}$ D. J. Eatough, J. J. Christensen and R. M. Izatt, J. Chem. Thermodynamics, 7, 417 (1975).

${ }^{4}$ P. Picker, C. Jolicouer and J. E. Desnoyers, J. Chem. Thermodynamics, 1, 469, 485 (1969).

${ }^{5}$ T. V. Charlu, O. J. Kleppa and T. B. Reed, J. Chem. Thermodynamics, 6, 1065 (1974).

${ }^{6}$ G. Olofsson, S. Sunner, M. Efimov and J. Laynez, J. Chem. Thermodynamics, 5, 199 (1973).

${ }^{7}$ G. Olofsson and I. Olofsson, J. Chem. Thermodynamics, 5, 533 (1973).

${ }^{8}$ J. W. Cobble, R. C. Murray, R. G. Grieger and T. Y. Ridley, paper VIII/8

${ }^{9}$ L. Espada, G. Pilcher and H. A. Skinner, J. Chem. Thermodynamics, 2, 647 (1970).

${ }^{10} \mathrm{~J}$. C. Ahluwahlia and J. W. Cobble, J. Am. Chem. Soc. 86, 5381 (1964).

${ }^{11}$ C. E. Vanderzee, M. L. N. Rodenburg and R. L. Berg. J. Chem. Thermodynamics, 6, 17 (1974).

${ }^{12}$ C. E. Vanderzee and L. J. Gier, J. Chem. Thermodynamics, 6 , 441 (1974).

${ }^{13}$ T. F. Young, Y. C. Wu and A. A. Krawetz, Discussion Faraday Soc. 24, 37 (1957).

${ }^{14}$ R. H. Wood and M. Ghamkar, J. Phys. Chem. 73, 3959 (1969). (See also other papers by Wood et al.)

${ }^{15} \mathrm{R}$. Arnek and W. Kakolowiez, Acta Chem. Scand. 21, 1449 (1967).

${ }^{16}$ I. Ahlberg, Acta Chem. Scand. 16, 887 (1962).

${ }^{17}$ S. A. Shchukarev, Z. U. Borisova and L. A. Baidakov, Zh. Obshch. Khim. 33, 353 (1960); (cf. Russ. J. Gen. Chem. 30, 377 (1960)).

${ }^{18}$ S. A. Shchukarev, S. A. Andreev and Z. U. Borisova, $Z h$. Obshch. Khim. 29, 2468 (1959); (cf. Russ. J. Gen. Chem. 29, 2430 (1959)).

${ }^{19}$ S. A. Shchukarev, Z. U. Borisova and A. M. Gusev, Zh. Obshch. Khim. 30, 3857 (1960); (cf. Russ. J. Gen. Chem. 30, 3811 (1960))

${ }^{20}$ L. J. Gier and C. E. Vanderzee, J. Chem. Eng. Data 19, 315 (1975).

${ }^{21}$ L. J. Gier and C. E. Vanderzee, J. Chem. Eng. Data 19, 323 (1975).

${ }^{22}$ R. L. Berg, Ph.D. Thesis, University of Nebraska (1974).

${ }^{23}$ R. L. Berg and C. E. Vanderzee, J. Chem. Thermodynamics, 7 , 219 (1975).

${ }^{24}$ R. L. Berg and C. E. Vanderzee, J. Chem. Thermodynamics, 7, 229 (1975).

${ }^{25}$ E. E. Messikomer and R. H. Wood, J. Chem. Thermodynamics, 7, 119 (1975).

${ }^{26}$ B. B. Owen and S. R. Brinkley, Jr., Ann. N. Y. Acad. Sci. 51, 753 (1949). 